\title{
Attraction of Tomicus yunnanensis (Coleoptera: Scolytidae) to Yunnan Pine Logs with and without Periderm or Phloem: An Effective Monitoring Bait
}

\author{
Rong Chun Lu, ${ }^{1,2}$ Hong Bin Wang, ${ }^{1}$ Zhen Zhang, ${ }^{1}$ John A. Byers, ${ }^{3}$ You Ju Jin, \\ Hai Feng Wen, ${ }^{2}$ and Wen Jian $\mathrm{Shi}^{2}$ \\ ${ }^{1}$ Research Institute of Forest Ecology, Environment and Protection, Chinese Academy of Forestry and The Key Laboratory of \\ Forest Ecology and Environment, State Forestry Administration, Beijing 100091, China \\ ${ }^{2}$ College of Urban Construction, University of Shanghai for Science and Technology, Shanghai 200093, China \\ ${ }^{3}$ U.S. Arid-Land Agricultural Research Center, USDA-ARS, 21881 North Cardon Lane, Maricopa, AZ 85138, USA \\ ${ }^{4}$ College of Plant Sciences, Beijing Forest University, Beijing 100083, China \\ Correspondence should be addressed to Hong Bin Wang, wanghb@caf.ac.cn
}

Received 6 October 2011; Revised 13 December 2011; Accepted 13 December 2011

Academic Editor: Qing-He Zhang

Copyright () 2012 Rong Chun Lu et al. This is an open access article distributed under the Creative Commons Attribution License, which permits unrestricted use, distribution, and reproduction in any medium, provided the original work is properly cited.

The Yunnan pine shoot beetle, Tomicus yunnanensis Kirkendall and Faccoli (Coleoptera: Scolytinae) is an important pest of Yunnan pine (Pinus yunnanensis Franch) in China. Experiments with host log baits were done to develop a pest monitoring system using host tree kairomone. Five Yunnan pine logs (each $10-15 \mathrm{~cm}$ diam. $\times 30-\mathrm{cm}$ long) in a trap-log bundle were treated by peeling periderm (outer bark) off to expose the phloem, and half of each log was covered with sticky adhesive to capture any attracted adult beetles. Significantly, more beetles were attracted and caught on the periderm-peeled logs (ca 30 beetles $/ \mathrm{m}^{2} \log$ surface $/$ day) than on untreated control logs with adhesive (ca $2.5 / \mathrm{m}^{2} /$ day). No significant differences were observed between catches on logs taken from lower or upper halves of Yunnan pines. T. yunnanensis flies mostly during the afternoon according to trap catches throughout the day. Attraction to the periderm-peeled logs decreased considerably when they were peeled further to remove the phloem, indicating phloem volatiles play a role in selection of the host by the beetle. The readily-available log baits appear useful for monitoring pine shoot beetle populations in integrated pest management programs.

\section{Introduction}

Tomicus yunnanensis (Coleoptera: Scolytinae) is a newly discovered and aggressive species of pine shoot beetle $[1,2]$. It was confused with $T$. piniperda (L.) in the past [1-3]. Recent studies show there are clear morphological, genetic, and ecological differences between these two species [2-4]. Compared with T. piniperda, T. yunnanensis is more harmful because it not only causes great growth losses, but also kills healthy pines by mass attack [4-6]. It has caused extensive mortality of Yunnan pines, Pinus yunnanensis Franch, in Yunnan province of China [1, 7]. Since the 1980s, more than 200,000 ha Yunnan pine forests have been killed $[3,4,7,8]$.

T. yunnanensis attacks trunks during maturation feeding in Yunnan province $[5,7]$. Trunk attacks last six to seven months from December to May, and peak attacks occur from January to March. Attacks on trunks begin in the crown and then spread down the bole. New adults fly to the shoots starting in March, the peak flight emerging in mid June. Maturation feeding lasts six to eight months $[3,5,7,8]$.

The extensive damage by T. yunnanensis indicates that as in other pine systems, effective monitoring and control are necessary [9-11]. However, there are no effective methods to manage the insect so far. It is reasonable to suspect there may be plant compounds from Yunnan pines that are attractive $[7,8,12]$. However, it is not known whether the beetles use a kairomone of Yunnan pines to locate hosts. The most popular method in the past has been to use trap log bundles to see if they are attractive to the beetles. This method is simple to try, but requires detection of odor signals (kairomone) from 
host or associated organisms that can be difficult to observe with catches of beetles using many logs $[8,13,14]$. Our objective was to design experiments that tested whether Yunnan pines release an attractive kairomone from various peridermand phloem-peeled bait logs that could serve as an effective method for monitoring and potential control of T. yunnanensis. The research should provide methods that avoid unnecessary work and improve bait log efficiency $[15,16]$.

\section{Materials and Methods}

2.1. Study Site Conditions. A series of experiments were conducted in a 300 ha plantation of Yunnan pines located on the mountain near Qujing city in Yunnan province $\left(25^{\circ} 14^{\prime} \mathrm{N}\right.$, $103^{\circ} 50^{\prime}$, and $1700-1800 \mathrm{~m}$ above sea level). The field site mainly consisted of Yunnan pines, Pinus yunnanensis L., and a small proportion $(<10 \%)$ of broad-leaved trees. Most of the Yunnan pines were infested with T. yunnanensis. The trees were $30-45$ years old and ranged from $10-15 \mathrm{~m}$ in height and $10-15 \mathrm{~cm}$ in diameter.

2.2. Experimental Design. Two experiments were conducted from December to February in 2006 and 2007. In the first experiment, to avoid any sex pheromone effects, six healthy Yunnan pines were cut whose trunks were free of bark beetle attacks (no obvious beetle entrance holes). All the tree trunks were cut into $30-\mathrm{cm}$ long logs. Among all the logs, 30 cut logs were randomly selected and the surface area of each log measured, then the periderm (outer bark) of the logs was peeled off leaving the phloem exposed (Figure 1(a)), and every five treated logs were placed in a trap log bundle. Another 30 cut logs were treated the same, but the phloem was also peeled from the logs (Figure 1(b)). The last 30 cut logs had only their surface area measured and were not peeled (Figure 1(c)). Half the surface area of each $\log (15 \mathrm{~cm})$ was covered with sticky adhesive supplied by Hebei Academy of Forestry to catch any bark beetles that landed. Finally all the cut logs in the 18 bundles were randomly hung at about $1.5-1.7 \mathrm{~m}$ height in trees. The distance between one trap log bundle to another was about $100-120 \mathrm{~m}$. In addition, six healthy Yunnan pines were randomly chosen and the trunk periderm was peeled off for $1.5 \mathrm{~m}$ of the trunk upward beginning $0.6 \mathrm{~m}$ above the ground, but the phloem was left in good condition, then half of the peeled trunk surface was covered with the adhesive every other $15-\mathrm{cm}$ height interval (Figure 1(d)). All six trees remained standing. The distance between each of these trees was also about 100$120 \mathrm{~m}$. The trap catches of the bark beetles were collected daily and species distinguished with a binocular microscope. This experiment was repeated monthly for three months (December to February in 2006 and 2007); with results of all months pooled to obtain a daily mean trap catch.

In the second study, four healthy Yunnan pines were cut down, each tree divided into two sections from the middle (lower half and upper half). Then a $1.5 \mathrm{~m}$ long log was cut from each section, and all the periderm peeled off with the phloem remain in good condition. Finally, each log was divided into five $30 \mathrm{~cm}$ long bolts and these were put in one trap log bundle; half the surface of each piece was covered with adhesive. The bundles from the top-half section and the bottom-half section were arranged in pairs (to give almost equal diameter) and hung up in trees at 1.5-1.7 m height. The distance between each trap log bundle was about 100$120 \mathrm{~m}$. The experiment was replicated each of three months for two years as in the first experiment. The trap catches of the bark beetles were collected each day and species distinguished with a binocular microscope.

2.3. Data Presentation and Analyses. Data were checked for normality and presented as mean \pm standard error. Variance analysis (ANOVA) was conducted with SPSS 11.5 (SPSS Inc., Chicago, IL, USA).

\section{Results}

The trapping efficiency of $\log$ bundles for $T$. yunnanensis was greatly affected by the log treatment method (Figure 2). Logs with the periderm peeled off and the phloem left were most attractive to T. yunnanensis, attracting roughly $30 \mathrm{~T}$. yunnanensis per day per square meter log surface. There were significant differences between the trap catches of T. yunnanensis among the other log treatment methods $(P<0.05$, Tukey's multiple comparison). The other two methods of treating the trap log bundles attracted much fewer T. yunnanensis. However, the logs with both periderm and phloem peeled off attracted slightly, but not significantly, more $T$. yunnanensis than the logs not peeled. The uncut pine trees attracted the fewest T. yunnanensis.

Dissection of the trunk (results not shown) indicated that the distribution of the entrance holes of T. yunnanensis is mainly in the mid and upper sections of Yunnan pine trees. Whether this pattern is affected by variations in a kairomone of Yunnan pine is unknown. To investigate this, logs from different parts of Yunnan pine trees were compared for attraction of T. yunnanensis. We found that logs from the upper half of Yunnan pine trees attracted a little more T. yunnanensis than sections from the lower half of the tree, but there was no significant difference $(P<0.05$, Tukey's paired-samples test, Figure 3).

The trap catches of T. yunnanensis during the day show that T. yunnanensis was trapped in the afternoon, the peak capture rate occurred from 14:00 to 18:00, while a few were trapped from 7:00 to 14:00. The peak time of capture was strongly affected by weather conditions; occurring a little earlier or later, or not at all under poor weather conditions. Figure 4 shows results under good weather conditions.

\section{Discussion}

The periderm is important to trees; the outer bark slows the release of water and organic volatiles from inside the tree. Once logs were peeled, their volatiles were released in much larger amounts, allowing the peeled logs to attract more $T$. yunnanensis than the unpeeled ones. Yunnan pine bark is known to contain many different monoterpenes (primarily $\alpha$-pinene and 3-carene) somewhat similar to Scots pine [17]. 


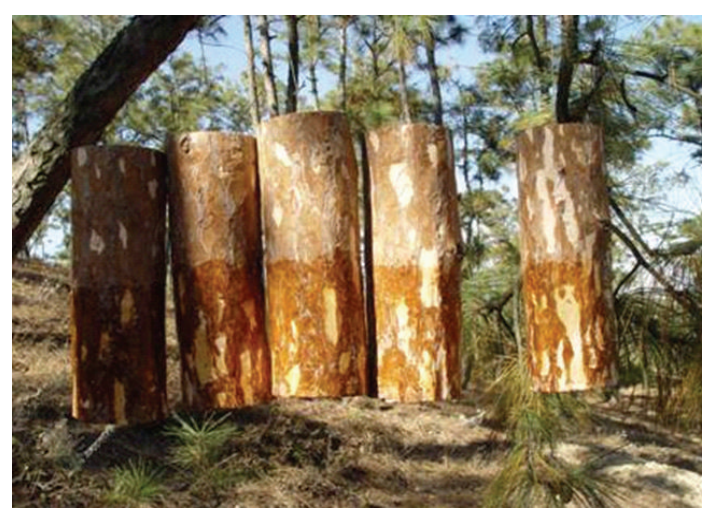

(a)

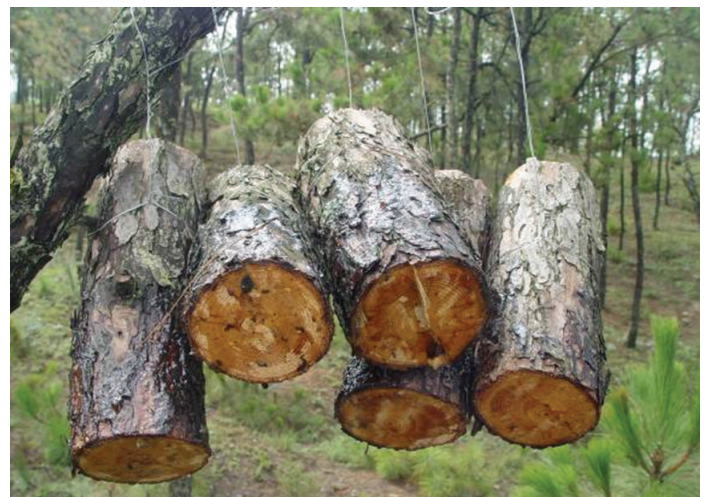

(c)

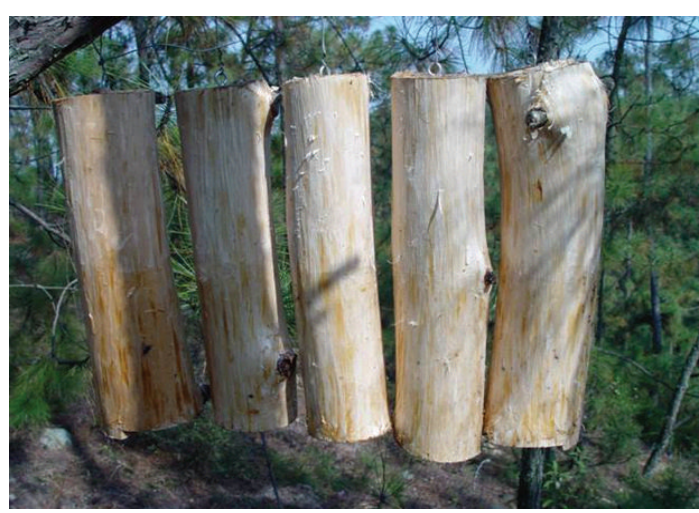

(b)

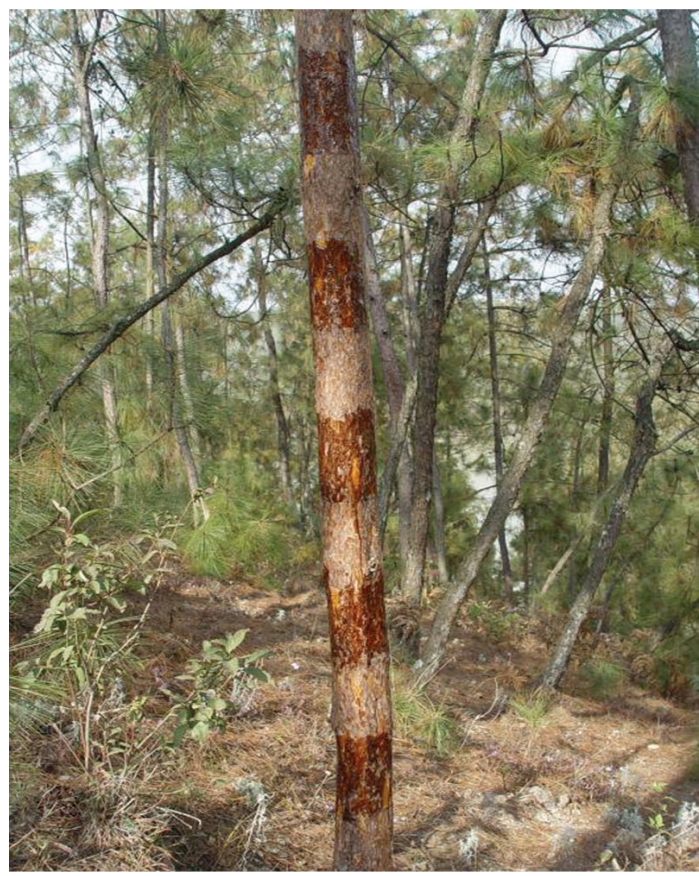

(d)

Figure 1: (a) Trap log bundles with periderm peeled off. (b) Trap log bundles with periderm and phloem peeled off. (c) Intact (not peeled) trap log bundles. (d) Standing Yunnan pine tree with periderm peeled off and every other $15 \mathrm{~cm}$ section covered with sticky adhesive (Qujing, Yunnan, China).

These volatiles may comprise a kairomone of various monoterpenes that was shown attractive to another Tomicus species, T. piniperda, in Sweden that colonizes Scots pine [12]. Interestingly, the peeled logs that retained the phloem were much more attractive to T. yunnanensis than the logs peeled of both periderm and phloem. This is surprising since monoterpenes should exude from the xylem tissues and cause attraction. However, this was not the case. Observations during the experimental study revealed that all the beetle galleries were found in the phloem, which means the phloem is the main food of the beetle, as in most bark beetles [18, 19]. The results suggest the odors released from this part of the tree are used as the kairomone by the beetles when searching for food. The phloem is the tree's main transport channel of photosynthetic nutrition. Perhaps the energy from phloem is needed to continue releasing resin (and kairomone). In any case, the experimental results from the logs treated by peeling off the phloem shows that once the log has lost its phloem, its ability to attract beetles is greatly weakened.

Trunk attacks by T. yunnanensis are a major cause of tree mortality in Yunnan province [20]. It is reasonable to use kairomone of Yunnan pine trees to monitor and aid in control of the beetles. Natural kairomone would be expected to be as effective as the best synthetic blends that require much research to elucidate. As an alternative to synthetic baits, one of the most popular methods is to use trap log bundles to monitor population levels of beetles. This method is simple and uses readily available resources, but does require significant labor and many logs. We peeled logs to improve the quantities of volatile chemical compounds released, making it possible to use fewer logs and trap more bark beetles. In addition, the peeled logs make it easier to count beetles that 


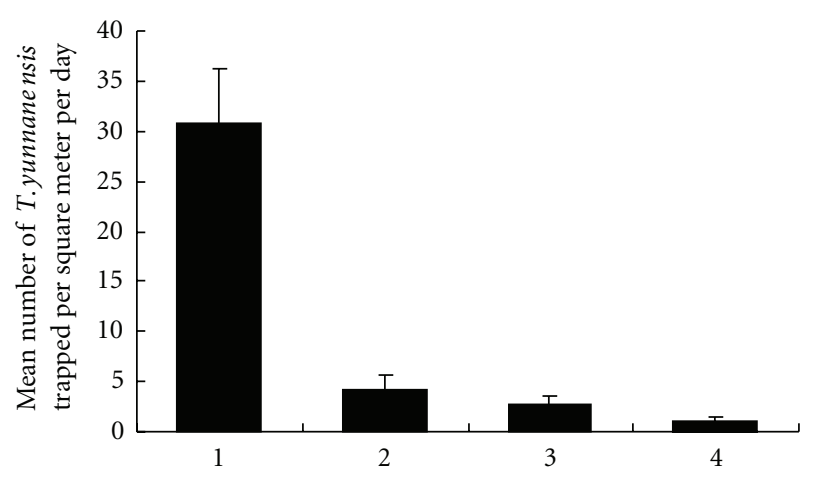

Figure 2: Daily mean trap catches $( \pm$ SE, $N=180)$ of $T$. yunnanensis attracted to: (1) periderm peeled logs, (2) periderm and phloem peeled logs, (3) intact (unpeeled) logs, and (4) standing periderm-peeled Yunnan pines (Dec.-Feb. 2006, 2007; Qujing, Yunnan, China).

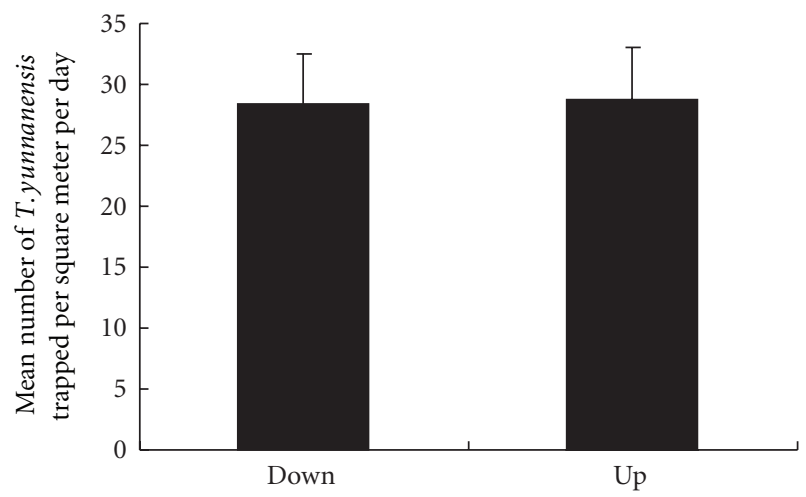

Figure 3: Daily mean trap catches $( \pm$ SE, $N=180)$ of $T$. yunnanensis on logs from lower-half (Down) and upper-half (Up) sections of Yunnan pines (Dec.-Feb. 2006, 2007; Qujing, Yunnan, China).

are attracted and caught, especially when the surface of the peeled logs is covered with sticky adhesive. Our experimental results show the logs peeled of periderm (outer bark) trapped the most T. yunnanensis. While the standing trees peeled in the same way attracted the fewest bark beetles. The standing trees should have not only had constitutive defenses but also inducible defenses [21-24]. The periderm was the most important defensive factor that protected the trunks. When the periderm of trees was peeled off, the constitutive defenses lost effectiveness to some extent, but this damage activated the strong inducible defenses [23]. If the trees were cut down, they lost the inducible defenses. The periderm is important because it not only retards water loss from trunks, but also prevents volatiles from rapidly evaporating from the phloem's resin canals. When the periderm was peeled off, the release rate of volatiles likely increased greatly and enhanced attraction. Logs which were not peeled trapped only a few bark beetles as did the logs peeled to remove phloem. This may happen because most of the kairomone came from phlo$\mathrm{em}$, so when the phloem was lost, the attractive ability was reduced, indicating that the phloem was the most important source of the kairomone. However, whether the kairomone is synthesized in phloem is uncertain.

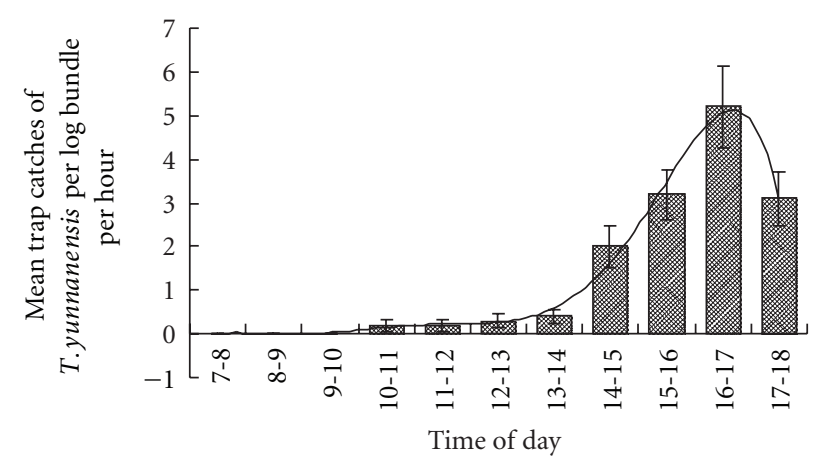

FIgure 4: Mean trap catches $( \pm \mathrm{SE})$ per hour of T. yunnanensis on periderm-peeled log bundles during the day (Dec.-Feb. 2006, 2007; Qujing, Yunnan, China).

Most T. yunnanensis were trapped in the afternoon; maybe because T. yunnanensis was more flight active in the afternoon. Consequently, the afternoon is the best time to study bark beetle behavior in regard to host selection and colonization. In nature, most of the T. yunnanensis attacks are found in the top section of the tree [25] but when we used different sections of the tree to attract and trap the beetle, there were no significant differences among the sections. Thus, there appears to be no obvious differences in kairomone release among the different sections from the lower and upper halves of the tree.

Here we present an efficient method to determine whether the kairomone of the host trees can be used to trap pest bark beetles, and whether it is possible to produce attractive baits from the host tree. Pine logs peeled of periderm as baits are easier and more effective compared with traditional log bait methods that use logs with intact bark.

\section{Acknowledgments}

The authors thank the Forest Pest Control Station of Qujing City, Yunnan province, for logistical support and field assistance. This study was funded by the Importing International Advanced Agricultural Science and Technology Research (2002-38) and the International Technological Cooperation Research (2006DFA31790).

\section{References}

[1] B. Långström, L. Lisha, L. Hongpin et al., "Shoot feeding ecology of Tomicus piniperda and T. minor (Col., Scolytidae) in southern China," Journal of Applied Entomology, vol. 126, no. 7-8, pp. 333-342, 2002.

[2] L. R. Kirkendall, M. Faccoli, and H. Ye, "Description of the Yunnan shoot borer, Tomicus yunnanensis Kirkendall \& Faccoli sp. n. (Curculionidae, Scolytinae), an unusually aggressive pine shoot beetle from southern China, with a key to the species of Tomicus," Zootaxa, no. 1819, pp. 25-39, 2008.

[3] Y. Hui and D. Xue-Song, "Impacts of Tomicus minor on distribution and reproduction of Tomicus piniperda (Col., Scolytidae) on the trunk of the living Pinus yunnanensis trees," Journal of Applied Entomology, vol. 123, no. 6, pp. 329-333, 1999. 
[4] Y. Duan, C. Kerdelhué, H. Ye, and F. Lieutier, "Genetic study of the forest pest Tomicus piniperda (Col., Scolytinae) in Yunnan province (China) compared to Europe: new insights for the systematics and evolution of the genus Tomicus," Heredity, vol. 93 , no. 5, pp. 416-422, 2004.

[5] H. Ye, "Occurrence, distribution and damages of Tomicus piniperda in Yunnan, Southwestern China," Journal of Yunnan University, vol. 20, pp. 361-363, 1998.

[6] H. Wang, Y. Zhang, and L. Li, "Bionomics of Tomicus piniperda in Yunnan," Forest Pest and Disease, vol. 25, no. 4, pp. 21-24, 2006.

[7] J. H. Sun, S. R. Clarke, L. Kang, and H. B. Wang, "Field trials of potential attractants and inhibitors for pine shoot beetles in the Yunnan province, China," Annals of Forest Science, vol. 62, no. 1, pp. 9-12, 2005.

[8] T. Zhao, N. Zhou, L. Li et al., "Tomicus piniperda trapping in damaged Pinus yunnanensis stands by trap log and living tree," Yunnan Forestry Science and Technology, vol. 95, pp. 53-57, 2001.

[9] R. N. Conner, D. Saenz, D. C. Rudolph, and R. N. Coulson, "Southern pine beetle-induced mortality of pines with natural and artificial Red-cockaded Woodpecker cavities in Texas," Wilson Bulletin, vol. 110, no. 1, pp. 100-109, 1998.

[10] M. Dobbertin and A. Rigling, "Pine mistletoe (Viscum album ssp. austriacum) contributes to Scots pine (Pinus sylvestris) mortality in the Rhone valley of Switzerland," Forest Pathology, vol. 36, no. 5, pp. 309-322, 2006.

[11] P. Martikainen, J. Kouki, O. Heikkala, E. Hyvärinen, and H. Lappalainen, "Effects of green tree retention and prescribed burning on the crown damage caused by the pine shoot beetles (Tomicus spp.) in pine-dominated timber harvest areas," Journal of Applied Entomology, vol. 130, no. 1, pp. 37-44, 2006.

[12] J. A. Byers, B. S. Lanne, J. Löfqvist, F. Schlyter, and G. Bergström, "Olfactory recognition of host-tree susceptibility by pine shoot beetles," Naturwissenschaften, vol. 72, no. 6, pp. 324-326, 1985.

[13] E. Bois, F. Lieutier, and A. Yart, "Bioassays on Leptographium wingfieldii, a bark beetle associated fungus, with phenolic compounds of Scots pine phloem," European Journal of Plant Pathology, vol. 105, no. 1, pp. 51-60, 1999.

[14] U. Kohnle, "Host and non-host odour signals governing host selection by the pine shoot beetle, Tomicus piniperda and the spruce bark beetle, Hylurgops palliatus (Col., Scolytidae)," Journal of Applied Entomology, vol. 128, no. 9-10, pp. 588-592, 2004.

[15] C. Chararas, C. Revolon, M. Feinberg, and C. Ducauze, "Preference of certain scolytidae for different conifers-a statistical approach," Journal of Chemical Ecology, vol. 8, no. 8, pp. 1093 $1109,1982$.

[16] J. A. Byers, "Attraction of bark beetles, Tomicus piniperda, Hylurgops palliatus, and Trypodendron domesticum and other insects to short-chain alcohols and monoterpenes," Journal of Chemical Ecology, vol. 18, no. 12, pp. 2385-2402, 1992.

[17] A. K. Borg-Karlson, M. Persson, À. Christiansson et al., "Relative amounts and enantiomeric composition of monoterpene hydrocarbons in Pinus yunnanensis Fr. and Pinus sylvestris L.," in Physiology and Genetics of Tree-Phytophage Interactions, vol. 90 of Les Colloques, pp. 101-110, INRA, 1999.

[18] J. A. Byers, "Chemical ecology of bark beetles," Experientia, vol. 45, no. 3, pp. 271-283, 1989.

[19] J. A. Byers and Q. H. Zhang, "Chemical ecology of bark beetles in regard to search and selection of host trees," in Recent Advances in Entomological Research, T.-X. Liu and L. Kang, Eds., pp. 88-111, The Higher Education Press, Beijing, China, 2010.
[20] H. Ye, "On the bionomy of Tomicus piniperda L. (Coleoptera: Scolytidae) in the Kunming region of China," Journal of Applied Entomology, vol. 112, no. 1-5, pp. 366-369, 1991.

[21] B. Langstrom, C. Hellqvist, A. Ericsson, and R. Gref, "Induced defence reaction in Scots pine following stem attacks by Tomicus piniperda," Ecography, vol. 15, no. 3, pp. 318-327, 1992.

[22] B. Långström, H. Solheim, C. Hellqvist, and P. Krokene, "Host resistance in defoliated pine: effects of single and mass inoculations using bark beetle-associated blue-stain fungi," Agricultural and Forest Entomology, vol. 3, no. 3, pp. 211-216, 2001.

[23] D. Wainhouse, D. R. Rose, and A. J. Peace, "The influence of preformed defences on the dynamic wound response in Spruce bark," Functional Ecology, vol. 11, no. 5, pp. 564-572, 1997.

[24] V. R. Franceschi, P. Krokene, E. Christiansen, and T. Krekling, "Anatomical and chemical defenses of conifer bark against bark beetles and other pests," New Phytologist, vol. 167, no. 2, pp. 353-376, 2005.

[25] R. C. Lu, H. B. Wang, Z. Zhang et al., "Coexistence and competition between Tomicus yunnanensis and T. minor (Coleoptera: Scolytinae) in Yunnan pine," Psyche, vol. 2012, Article ID 185312, 6 pages, 2012. 

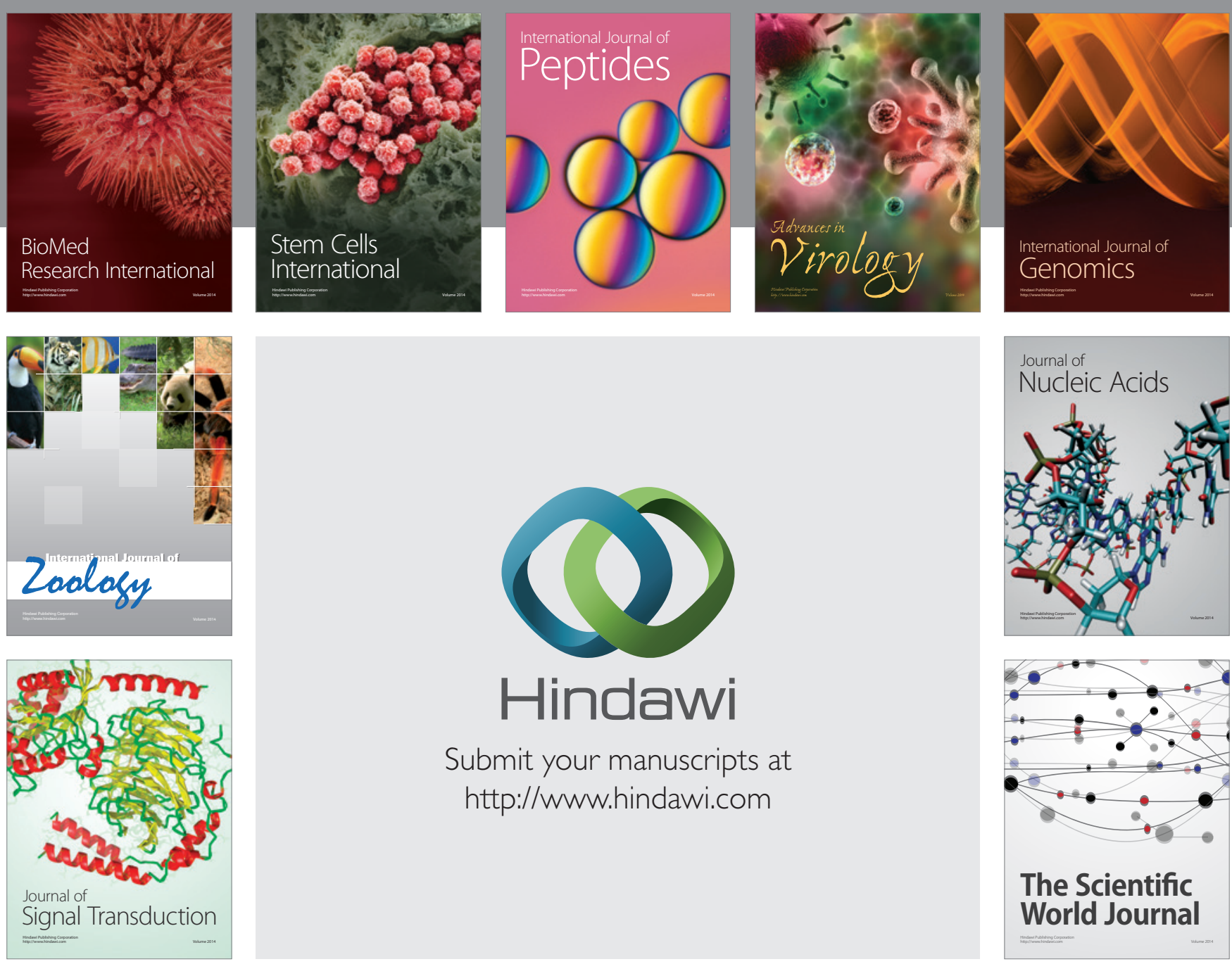

Submit your manuscripts at

http://www.hindawi.com
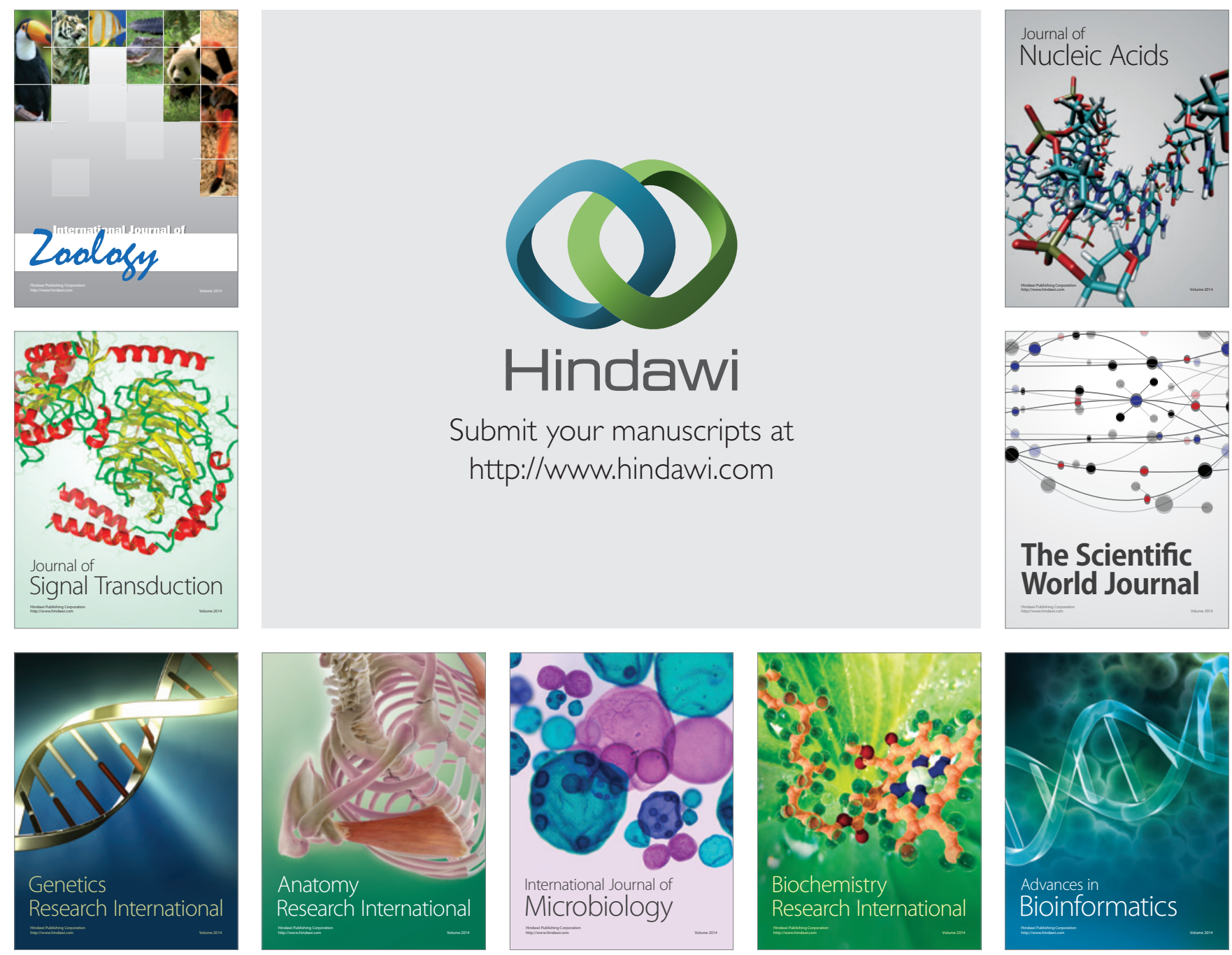

The Scientific World Journal
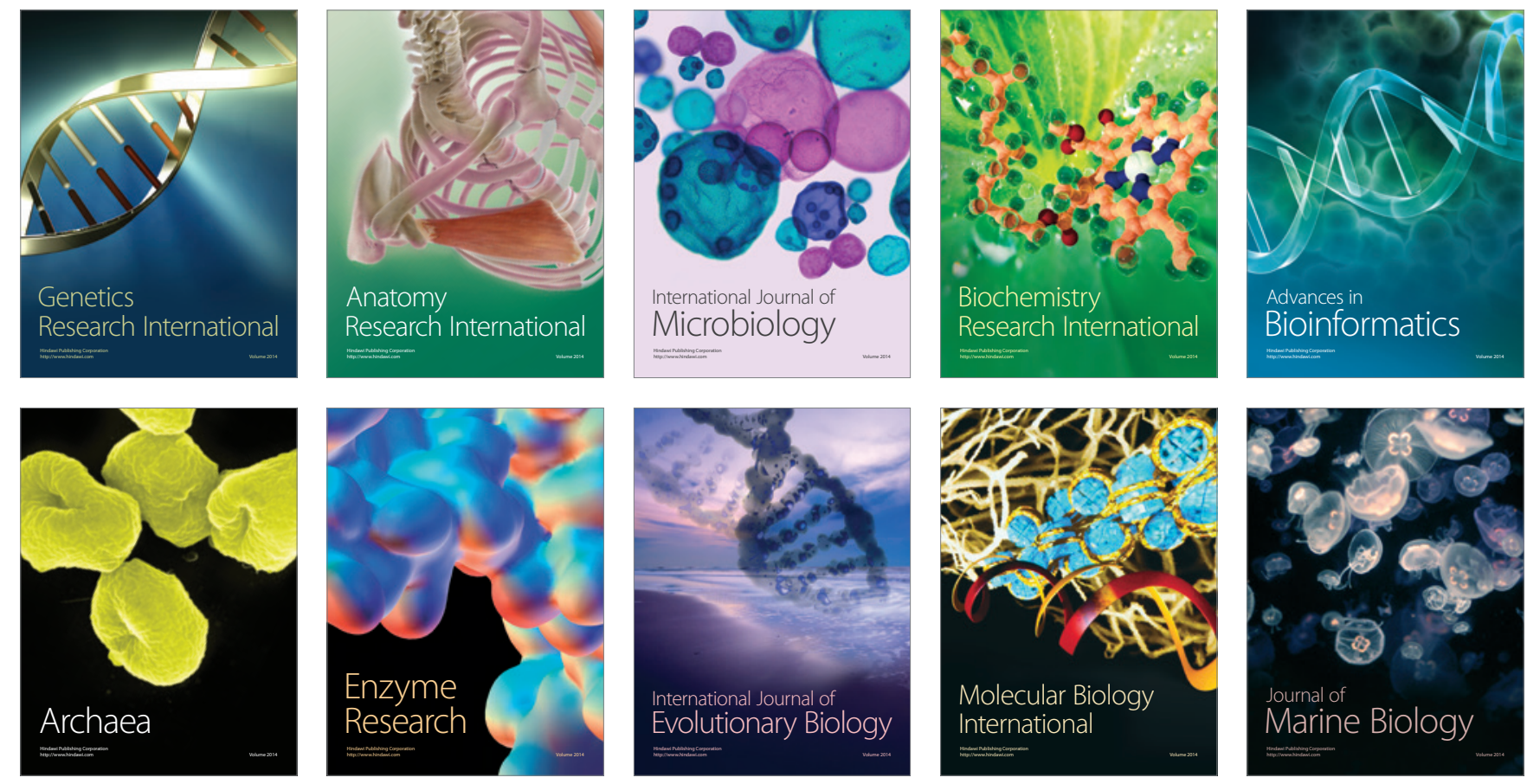